\title{
ORAL HEALTH SURVEILLANCE IN NSW
}

Mary Osborn*

Public Health Officer

NSW Public Health Officer Training Program

Oral health has been defined as: 'A standard of health of the oral and related tissues which enables an individual to eat, speak and socialise without active disease, discomfort or embarrassment and which contributes to general well being' . ${ }^{1}$

The NSW Oral Health Branch is currently developing indicators that seek to identify factors that contribute to the burden of oral disease in the community. ${ }^{2}$ Indicators and outcomes will be used to develop policies and strategies to address areas where the burden of oral disease can be reduced and to optimise the use of resources. This process will involve a collaboration by experts in oral health, and build on work already undertaken in oral health surveillance.

\section{DENTAL CARIES}

The first set of core indicators to be developed focus on dental caries. Dental caries is the most costly diet-related disease in Australia, ahead of coronary heart disease, hypertension and diabetes. ${ }^{3}$

\section{Children}

The dental caries experience of NSW children as sampled by the 1993 Child Dental Health Survey varied between Area Health Services. The Save Our Kids Smiles (SOKS) program has been operating in NSW since 1996. This program offers free oral health assessments at schools. Parents of children assessed as having oral problems can choose to seek treatment either through private dentists or public child oral health clinics.

Data describing the oral health of children aged 0 to 4 years are not readily available, as these children do not usually access the SOKS program. Hospital separations for the removal or restoration of teeth among children under the age of four years increased during the period 1988-89 to 1991-92, subsequently declined, and rose again slightly in $1994-5 .{ }^{4}$

Oral care is available free to children to the age of 14 , or to 18 years if they are attending a high school. From the age of 15 years, the child must be a dependent listed on a Health Care Card or Pensioner Concession Card, or hold such a card in their own right, to access public health care. Any child requiring relief of pain and any further nonurgent treatment after the initial relief of pain may access public oral health clinics around NSW.

\section{Adults}

In 1995-96, the adult dental caries status in NSW increased from a mean DMFT (mean number of decayed, missing and filled teeth) of 6.2 for those aged less than 25 years to a mean DMFT of 19.4 for those aged 65 years and over. ${ }^{5}$ This implies that, for the NSW population, half of their teeth will be decayed, missing or filled by the age of 65 . The potential for health gain from reducing dental caries is probably the best of any oral disease, and there are well documented evidence-based practices for achieving this. ${ }^{6,7}$

\section{Dental Treatment}

In 1994, more than 80 per cent of dental treatment was provided by the private sector. ${ }^{8}$ Private care is available to all sectors in the community, but the cost and extent of services offered varies from provider to provider. It was noted by the 1997 Senate inquiry into public dental services that the cost of private care inhibits people from seeking or maintaining a good standard of oral health. ${ }^{9}$ The disparity between the cost of oral treatment and income level means that those at the lower income levels are more likely to use emergency departments for care. A cycle of emergency care develops, resulting in patients receiving oral treatment that eases the immediate burden of pain, but this does not necessarily address the underlying problems.

In Australia, a fundamental oral care problem is access to services. ${ }^{10}$ High percentages of low-income individuals and health care cardholders face direct out-of-pocket costs when using private sector oral health services. Affordability and hardship were also associated with a perceived need for oral treatment and individuals' rating of their own oral health in comparison to other people of a similar age. ${ }^{11}$

\section{CONCLUSION}

An oral health surveillance strategy could monitor: outcomes or health gains that oral health can provide; trends in oral disease; benefits through differing types of service provision; clinical disease management; the effect of oral health on a person's well being; and the relationship between an individual's general and oral health status.

However, adequate monitoring of the oral health status of the NSW population will require some fundamental changes in collecting information across all age groups. The last national oral health survey was conducted in 1987. ${ }^{12}$ This offers baseline data to benchmark subsequent surveys. The NSW Oral Health Branch's indicator initiative is also an attempt to introduce an evidence-based approach to ensure an optimal standard of oral health delivery.

\section{REFERENCES}

1. Fuller SS, Blinkhorn A. Achieving the targets for oral health. Manchester: Eden Bianchi Press, 1995.

2. NSW Health. Strategy for population Health Surveillance in NSW. Discussion paper. December 1997.

\footnotetext{
* Currently with United Medical Protection
} 
3. Australian Institute of Health and Welfare. Australia's health 1998: The sixth biennial health report of the Australian Institute of Health and Welfare. Canberra: AIHW, 1998.

4. Public Health Division. The Health of the People of New South Wales: Report of the Chief Health Officer. Sydney: NSW Health Department, 1997.

5. Brennan DS, Spencer AJ. Prospective adult dental programs survey 1995-96. AIHW DSRU, University of Adelaide, Adelaide, 1996.

6. Lewis DW, Ismail AI. Preventive Dental Care (Chapter 36). Canadian Task Force on the Periodic Health Examination. Ottawa: Canada Communication Group, 1994.

7. US Preventive Services Task Force cited in Canadian Task Force on the Periodic Health Examination. Canadian guide to clinical preventive health care. Ottawa: Canada Communication Group, 1994: 408-431.
8. Allister J, Stewart J, Spencer J. Dental satisfaction survey 1994. AIHW DSRU, University of Adelaide, 1995.

9. Australia, Parliament. Inquiry into public dental services: Report from the Senate Community Affairs References Committee, Canberra, 1998.

10. Spencer J. Key problems, target groups and policy directions. In: Dental care for adults in Australia. AIHW DSRU, University of Adelaide, 1993.

11. Spencer J. Affordability and hardship in purchasing dental care. In: Dental care for adults in Australia. AIHW DSRU, University of Adelaide, 1993.

12. Barnard PD. National oral health survey: Australia 198788. Canberra: Commonwealth of Australia, 1993. ISBN O 644292351 . F

\section{ORAL HEALTH NEEDS OF THE ELDERLY}

\section{Peter Lloyd King}

Staff Specialist

Special Care Dentistry

Westmead Centre for Oral Health

This article describes the oral health of elderly Australians using evidence provided by a number of local studies.

\section{INTRODUCTION}

It is generally accepted that 65 and over refers to the elderly population. At the turn of the century, only four per cent of Australian residents were aged 65 and over. That figure had risen to 12 per cent by 1979 , and it is expected to reach between 24 and 26 per cent by $2051 .{ }^{1}$

There is a trend away from edentulousness (having no natural teeth) in the elderly. In 1979, 60 per cent of elderly Australians were edentulous. By 1989, this figure had dropped to 44 per cent, and it is projected that only about 20 per cent of elderly Australians will be edentulous by 2019. There is also an increase in the number of natural teeth among those who have at least one natural tooth. This aging population with more natural teeth has resulted in growth in the 'pool of teeth' and, therefore, in the 'pool of teeth requiring treatment'. ${ }^{2}$

\section{ORAL HEALTH PROBLEMS OF THE ELDERLY}

The predominant oral health problems of the elderly include dental caries, periodontal disease, dry mouth (xerostomia), tooth wear and oral cancer. ${ }^{3}$ Recurrent caries around failing restorations, cervical caries (around the neck of the tooth) or root caries are the most common dental caries in the elderly. ${ }^{3,4}$ The prevalence of periodontal disease appears to increase with age, which may reflect an accumulation of disease over time rather than enhanced susceptibility. The number of teeth that need to be extracted due to periodontal disease increases with age. ${ }^{3}$ Dry mouth is a common complaint of elderly people, a subject discussed in Mark Shifter's article in the March issue of the Bulletin (Volume 10, Number 3). The progressive impact of smoking and drinking on the development of soft tissue lesions is more apparent in older adults, and the prevalence of oral cancer increases with age. ${ }^{3}$

\section{IMPACT OF ORAL HEALTH ONTHE WELLBEING OF FUNCTIONALLY INDEPENDENT AND INSTITUTIONALISED ELDERLY AUSTRALIANS}

The impact of oral health on the wellbeing of elderly people in Australia has been investigated in both the institutionalised elderly and the functionally independent elderly.

In South Australia 1,217 non-institutionalised people aged 60 years and over completed a questionnaire containing 49 questions about the effect of oral conditions on their comfort levels and functional abilities. Conditions such as difficulty chewing, discomfort during eating and avoidance of foods 'fairly often' or 'very often' were reported by more than five per cent of dentate persons 